\title{
Information and communication technology and the home environment
}

\author{
Andy Sloane \\ CoNTACT Research Group, School of Computing and IT, University of Wolverhampton, \\ Lichfield Street, Wolverhampton U.K
}

\begin{abstract}
The home is the scene of the most intense use and production of information. Many of the modes that are used for living can now be enhanced by the use of information and communication technology (ICT). This in turn enhances interpersonal relationships and brings the virtual into the real environment of the home as part of everyday life. This technological enhancement will depend on the use and development of information systems that can provide easy-to-use and intuitive interfaces for this new style of computer-enhanced living as part of a comprehensive home information system. Much research and development of ICT is aimed at the home but falls short of this level of integrated use with many devices being proprietary and isolated from others and ignoring much of what actually takes place in homes. Many devices are solely aimed at entertainment and ignore many of the real issues of interpersonal communication and interaction. This paper discusses these issues in the context of research that is being carried out by a number of different teams investigating the home environment.
\end{abstract}

Key words: Home; Information and communication technology; Social context

\section{INTRODUCTION}

The developments in information and communication technologies (ICT) are changing the nature of the home in the $21^{\text {st }}$ century. Not only are homes becoming physically more "wired" but they are also becoming more "virtual" with the concept of the home changing to incorporate these developments. Many commentators have shown changes taking place in the home environment over the years and others have shown the changes in behaviour brought about by the use of modern ICT $[1,2,3]$. When taken

The original version of this chapter was revised: The copyright line was incorrect. This has been corrected. The Erratum to this chapter is available at DOI: 10.1007/978-0-387-35609-9_29 
together these effects can be profound and bring about new configurations of social and inter-personal organisation that were not possible in the past. These developments will also have an influence on the information environment used by the occupants of the home.

\section{HOMES}

The changes in the home environment encompass the virtual and the distributed [4] in much the same way as businesses and enterprises. These have become "distributed" on a global scale and "virtual" via communication networks such as the Internet. Homes can now take advantage of the technology to bring people together and reinforce relationships and social groupings[5] in the same way as larger organisations. However, whilst this is possible it is not happening to a profound degree in practice. Many factors militate against such a change to society: individual psychology, market forces, economics, peer group pressures, etc.

The virtual: The concept of the virtual in the home is readily exemplified with reference to the Internet. Many users now use the Internet as a tool to store home information and to share it with others, exchanging email and using chat services. These inhabitants of "cyberspace" are using virtual extensions of the home on an everyday basis to re-define their living space or sphere of influence.

The distributed: The concept of the distributed is more rooted in modern life practices than in technology but many "families" and other social groupings are now living apart in a highly distributed manner. Whilst this is nothing new, the opportunity to incorporate distributed dwellers within the information environment of a "distributed" home or cyberhome is now possible.

The combination of virtual and distributed living allows new modes and functions of life to become apparent in the home. The "extended family" takes on a new meaning with people in any country able to take part in information sharing. The producer-consumer also takes root in the new virtual and distributed individual economy of the home regenerating the ancient Greek "Oikos" concept[6] giving a new slant on a very old scheme of life. The original Oikos was that way of living that incorporated home, work and community in a relatively small, shared space. However, the new way to achieve this Oikos is via distributed and virtual partners and interactions making a less tangible prospect than in past times. 
The possible changes to the everyday existence of home dwellers can be summed up as a shift from real to virtual modes of living and working; and a move from the home-centred life to a more distributed way of living.

\section{THE TECHNOLOGY}

The majority of computer technology that is currently in the home is derived from commercial machinery and this is primarily designed to be used in an office environment for particular standard tasks. The home is completely different from work even though many people now work from home [7], [8]. This difference now requires more recognition particularly in the area of Human-Computer interface and usability.

As an example, consider a home where there are three generations of a family, where one member is elderly and has difficulty in movement and another is young and has not yet learnt how to use a keyboard. Both of these special cases require attention. However, the vast majority of computing equipment is directed at the middle ground of people who are both physically and mentally capable of using it.

In addition to the interface requirements of some users, the home is often more demanding than the office in terms of the type of computing that is required of the $\mathrm{PC}$. Whereas many office computers do little more than word processing, the hi-tech wired home has a complex multimedia requirement that needs the most modern processors, the best graphics capability and a home storage requirement that is increasing rapidly. The other area of commonality with the commercial environment that has yet to reach into many homes is the use of networks. The home often has only one primary computing device (a PC) but there are more and more devices [13] that contain processors or process information in the home and these devices could all be linked together to form a complete home information system.

The technology of home information systems is still in its infancy[12] and there are improvements to be made in both hardware and software to make it more usable in the home. The tasks that are required of a home information system are varied and need specific reference to the users' requirements in the home setting and there is also a need to process the many types of information from the various devices that can be attached to the network. The current standards for networks are capable of coping with the home requirements, however the situation of software is very different - the home requirement is, as has been shown, very specific and this is the area that is crucial to the development and uptake of home information systems. 


\section{INTERPERSONAL RELATIONSHIPS}

Part of the home requirement of computing is to support the everyday communication (see [12]) between people and this in turn supports a variety of inter-personal relationships. This is a complex requirement as people communicate in many different ways for different purposes. The framing relationships of the participants also have an effect on the communication process.

The many different types of communication that take place in the home have been the subject of much recent research, notice-boards [9], communicating photo-frames [10], and standard email [11]. These have been used to provide both explicit and implicit communication between people. Many home situations require very different features from software than the more structured environment of the office. For example, there is often no specific security requirement for communication between users within the home and software does not need to enforce password security for logon to the service - indeed many of the features that are required in an office environment are positive disadvantages in the home - delaying users, causing unnecessary input and having excess features. Home communication software to support interpersonal relationships needs specific attention to the interface and usability which will facilitate easy use and multi-purpose interaction without multiple changes of interface or slow loading of software components.

Other inter-personal communication uses indirect interaction between sender and receiver to achieve user "comfort" i.e. the software is used in the background of everyday life to enhance the "life-experience" and provide reassurance for the participants (see [10]). Many situations that are not currently possible with existing technology could exist in the home of the future; many existing technologies could be adapted to provide new forms of communication for home dwellers. Inter-personal communication in all its forms is a crucial part of everyday life with technological support it can be advanced to provide many channels of communication between people that have only been dreams until now, and many channels that will enhance "life".

Technology that finds its way into the public arena often has different uses from those envisaged by its inventors or developers and inter-personal communication devices are no different. For example, the mobile phone has developed into an everyday tool for many sections of society that were not among the initial audience of intended users. Also, technology specifically designed for use in the home can often not become successful if the design and usability are such that it is difficult to interact with it simply and easily. A good example of this is found in the many forms of software that exist for 
home-related tasks. Many of which are complex and difficult to use compared to the traditional paper-based system.

\section{THE INFORMATION ENVIRONMENT OF THE HOME}

As will be apparent from the previous two sections the information environment of the home is constantly changing the technology used to process incoming information is constantly changing and the ability to use this and other information to aid or enhance information production in the home is relatively novel. However, the information environment of the home is extremely complex with a multiplicity of interlocking tasks needing constant attention and monitoring. This complexity is only recently becoming the focus of attention of ICT developers with the commercial environment having been comprehensively covered by software and hardware in the past.

The information that is used in the home consists of all the data types that encompass multimedia and this diversity (which is endemic in the home environment) needs full attention. The office environment, while using multimedia in some ways and in a few applications does not have the exacting requirement of most homes.

Homes have many sources of information in all its forms, text from books, magazines and newspapers, image from photographs, advertisements and other printed sources, sound from radio, cassettes and telephones and video from television, video cassettes and camcorders. This diversity in the home is currently accommodated by a number of different devices and storage mechanisms that require many different ways of handling, using and physically storing. The growth of computing and networks in the home will allow this diversity of information media to be incorporated into a single system or network of devices for home use and storage. However, the marketing of new specifically targeted devices is in conflict with this idea of integrated universal storage. Other drawbacks to single devices of mass home information storage that are apparent from commercial experience, such as centralising storage and reliance on single pieces of technology may also militate against such a move in the future.

\section{CONCLUSIONS}

The home, and the relationships it fosters and creates, is central to the way in which life is lived. It provides the physical and information environment for everyday existence. In some cases it also provides the base for work and 
leisure. It is now possible to combine the various sources of information used in the home into a comprehensive system for processing and storagethis enhances the range of possibilities of using the information and supporting the communication process, and allows technological support for fundamental processes of human existence such as inter-personal relationships.

This support is not yet widely available and not seen by many developers to be a worthwhile avenue of production. However, the many tools for communication that exist have all shown how they can enhance this process. The further use of ICT in the home will add to this growing range of possibilities but the process of developing the right technology for home users may be a long and difficult journey.

\section{REFERENCES:}

[1]. Bjerg K (1988) "Impact of home interactive telematics on the household", in van Rijn F, Williams R (eds.) Concerning Home Telematics, Elsevier Science, North Holland, Amsterdam

[2]. Venkatesh A (1996) "Computers and other interactive technologies for the home," Communications ACM, 38, 12, 47-54

[3]. Sloane A and van Rijn F (2000) Home informatics and telematics: information, technology and society. Kluwer, Boston, MA.

[4]. Sloane A (1994d), "Homelink: An international collaboration for HOIT", Proceedings of World Computer Congress, Hamburg, September 1994.

[5]. Ling R (2000) "Direct and mediated social interaction" in Sloane A and van Rijn F (2000) Home informatics and telematics: information, technology and society. Kluwer, Boston, MA.

[6]. Sloane A (1995) "The distributed home environment and the new OIKOS", in A Dix \& $\mathrm{R}$ Beale(Eds), "Remote Co-operation: CSCW issues for mobile and teleworkers", Springer, London.

[7]. Pierson J (2000) "ICT appropriation by small businesses" in Sloane A and van Rijn F (2000) Home informatics and telematics: information, technology and society. Kluwer, Boston, MA.

[8]. Sturesson L (2000) "The paths of work and ICT into the home" in Sloane A and van Rijn F (2000) Home informatics and telematics: information, technology and society. Kluwer, Boston, MA.

[9]. Huang W, Harris A J and Sloane A (2000), "Web-based noticeboard" in Sloane A and van Rijn F (2000) Home informatics and telematics: information, technology and society. Kluwer, Boston, MA.

[10].Go K, Carroll J M and Imamiya A (2000), "Familyware", in Sloane A and van Rijn F (2000) Home informatics and telematics: information, technology and society. Kluwer, Boston, MA.

[11].Buckner K and Gillham M (2000), "Using email for social and domestic purposes" in Sloane A and van Rijn F (2000) Home informatics and telematics: information, technology and society. Kluwer, Boston, MA.

[12].Huang W, Harris AJ and Sloane A (2000), "Home Information Systems: Design and configuration" University of Wolverhampton Internal research report.

[13]. Gillett S E, Lehr W H, Wroclawski J T and Clark D D (2001), "Do Internet appliances threaten Internet innovation", IEEE Communications, 39, 10, 46-51 